\title{
A miRNA-PEPTIDE FUSION AS A VACCINE CANDIDATE AGAINST THE NOVEL CORONAVIRUS (COVID-19). EXOSOMES AS POTENTIAL BIOMARKERS OF SARS-COV-2 IN LUNG: AFTER AND BEFORE VACCINATION LCR_2020_B008-13
}

Journal of Bioscience \& Biomedical Engineering

Research Article

\author{
${ }^{*}$ CRUZ-RODRIGUEZ L L ${ }^{1,2,3}$, DILSIZ N ${ }^{4}$, ZIARATI P ${ }^{5}$, LAMBERT BROWN D ${ }^{6}$, HOCHWIMMER B ${ }^{7}$, \\ ZAYAS TAMAYO AM ${ }^{8}$, SANCHEZ BATISTA L $^{8}$, MORADI $\mathbf{M}^{9}$
}

${ }^{1}$ CEO, ELIDAN genome SAS, 1 avenue du Lycée, 77130 Montereau

Fault Yonne; France.

${ }^{2}$ CEO, ELIDAN Dynamic LLC, 1602 Windermere Way, Tampa, FL,33619, USA.

${ }^{3}$ ExCELab Co. Ltd., Manager Director of Environmental Biotechnology Department., Jamaica.

${ }^{4}$ Molecular Biology and Genetics, Faculty of Engineering and Natural Sciences, Istanbul Medeniyet University, Istanbul, Turkey.

${ }^{5}$ Head of Nutrition and Food Sciences Research Center, Tehran Medical Sciences, Islamic Azad University, Tehran, Iran.

${ }^{6}$ CEO, Family Physician, FCMC \& ExCELab Co. Ltd, Jamaica.

${ }^{7}$ CEO, Hochwimmer B. \& Asso. Pty Ltd, Albury, NSW, Australia.

${ }^{8}$ ExCELab Co. Ltd., Environmental Biotechnology Department, Jamaica.

${ }^{9}$ Department of Cell \& Molecular Biology, Faculty of Biological Sciences, Kharazmi University, Tehran, Iran.

\author{
"Correspondence author \\ Dr. CRUZ-RODRIGUEZ Luis \\ CEO, \\ ELIDAN Dynamic LLC \\ 1602 Windermere Way \\ Tampa \\ FL, 33619 \\ USA \\ Email : 1cr@elidan-genome.com, \\ luis.cruzrguez@gmail.com
}

Submitted : 04 May 2020 ; Published : 25 May 2020

\begin{abstract}
Anew coronavirus named Covid-19 was reported in Wuhan, China in December 2019. The first time thesecases werepublished theywereclassified as "pneumonia of unknownetiology". The etiologyof thisillness is now attributed to anovel virus belonging to the coronavirus (CoV) family, COVID-19. Different from both MERS-CoV and SARS-CoV, 2019-nCoV it is the seventh member of the family of coronaviruses to infecthumans. We havedesigned apreventive vaccine in Silicoaimed toprotectagainst Covid-19 infection and transmission. Our analysis identified 16 microRNA (miRNA) with theorical Exosome Affinity (EA) with peptide among 85.44-92.84 range. According to antiviral monitoring after and before vaccination using the candidate miRNA-peptide number 13 (LCR_2020_B008-13) with value EA=92.84 Ro. We proposed the exosomes as biomarkers of SARS-Covid-2 in lung: after and before vaccination. Due to, the miRNA-peptides, in Silico, manifesting highly affinity with exosomes, where our chimera LCR 2020 B008-13 could reach a representative activity against the Covid-19virogenes due to "exosome sequestering"; and also, the treatment of cancer diseases due to "podosome depletion" in metastasis stage.
\end{abstract}

Keywords: Covid-19, Vaccination, Lung, Chimera miRNA-peptide, Biomarkers, SARS-CoV-2, Theorical Fusion Value Stability (FS), Theorical Fusion Value Exosome Affinity (EA), Plasma Sample, Preventive Vaccine in Silico, Exosome, Podosome, Antiviral LCR_2020_B008-13, Nanoplate-Based Digital PCR, Cancer, Metastasis 


\section{Introduction}

According to the World Health Organization (WHO), viral diseases continue to emerge episodically and represent a serious issue to public health. In the last twenty years, several viral epidemics such as the severe acute respiratory syndrome coronavirus (SARS-CoV from 2002 to 2003, and H1N1 influenza in 2009, have been recorded. In December 2019, a cluster of patients with pneumonia of unknown cause was linked to a seafood wholesale market in Wuhan, China. A previously unknown betacoronavirus was identified through the use of unbiased sequencing in samples from patients with pneumonia [1].

January 10, 2020, the first 2019-ncov genome was sequenced, followed by five subsequent viral genome sequences [2]. The new coronavirus, formed a clade within the subgenus Orthocoronavirinae, sarbecovirus subfamily. The first time these cases were published they were classified as "pneumonia of unknown etiology." The Chinese Center for Disease Control and Prevention (CDC) and local CDCs organized an intensive outbreak investigation program. The etiology of this illness is now attributed to a novel virus belonging to the coronavirus (CoV) family, COVID-19. Different from both MERS-CoV and SARS-CoV, 2019-nCoV it is the seventh member of the family of coronaviruses to infect humans [3].

The clinical range of the disease, new diagnostics, prevention and treatment strategies are in process of development. Unfortunately, insufficient research leading up to purported species-species viral transmission is alarming. We know they are more frequently episodic, yet always assume a systemic closed biology. This may be a faulty discipline assumption since the increasing episodic nature of viral transmission bears scrutiny on potential physiographic-climactic links. These in turn are open to geogenic-geological connections with terrain biology and ecology. The whole biological cycle of the virus de and host and the evolution of the epidemic, especially when the epidemic will reach its peak is unknown. Terrain-controlled genomic studies in soil geo-microbiology and invertebrate Medical Geology to higher species-species transmissions studies are recommended. This may extend the viral genomic phylogenic trees beyond the species-species barriers and diversity of potential future impacts. Geologists do not consider the possibility of spreading the disease by air, water, and earth. The discipline of Medical Geology can translate this enigmatic situation using its potential to understand the planet and human health relationships $[4,5,6]$.

One aim of this is to better understand potential dormant repositories of outbreaks and potential spread of those repositories, together with potential geogenic terrain factors and triggers. Integrated research in vaccine testing with such 'wild type' genomic diversity research is recommended to be also open to viral Medical Geology studies, as a new discipline $[7,8,9]$.

A better wild-type viral genomics understanding leading up to the current pandemic of Covid-19 is needed along with research into potential dormant repositories of outbreaks and the spread of those repositories, geogenic terrain factors and triggers. This will help understand the episodic, recurring and frequent nature of outbreaks and potential virulent and contagious future outbreaks. Here we have identified a miRNA-peptide fusion: $[10,11,12]$.

\section{COVID-19 Vaccination \& Exosomes}

The pandemic caused by a novel virus strain Covid-19, has led to over 320,000 deaths in over 185 countries worldwide. Importantly, it attacks people mainly with heart, lung, diabetes, and kidney disease. After the increasing number of SARSCoV-2 infections all over the world, researchers and clinicians are struggling to find a vaccine or drug to treat this viral infection.

The betacoronavirus SARS-CoV-2 is an enveloped ranging from $30 \mathrm{~nm}$ to $120 \mathrm{~nm}$ in diameter and seventh member of the Coronaviridae family. It has a positive-sense single-stranded RNA genome of 29,903 nucleotides with a 5 '-cap structure and 3 '-poly A tail that interacts with the nucleoprotein. This genome encodes five structural proteins including the spike glycoprotein $(\mathrm{S})$, the nucleocapsid protein $(\mathrm{N})$, the membrane protein $(\mathrm{M})$, RNA dependent RNA polymerase (RdRp), the small envelope glycoprotein (E), and several nonstructural proteins most of which, like in other coronaviruses, are of unknown functions. The expressed $\mathrm{S}$ protein $(180 \mathrm{kDa})$ is heavily glycosylated in the golgi apparatus then transferred to the surface of the virion vesicle [13J.

The RdRp is one of the most versatile enzymes of RNA viruses that is indispensable for replicating the viral RNA genome as well as for carrying out transcription[14].

\section{Virus genomic region targeted by virus and host miRNAs}

Viral diseases are difficult to predict, which requires prompt responses to their occurrence. Therefore, novel approaches in viral disease prevention, early detection, diagnosis and personalized therapy is required. All viruses multiply using a nucleic acid synthesis system and a protein synthesis system in an infected cell. In animal cells, $65 \%$ of the protein synthesis is controlled by miRNA (miRNA inhibiting target mRNA) $[15,16]$.

The miRNA was widely found in plants, animals and some viruses including SARS-CoV-2 and involved in a variety of biological processes. It is a small non-coding RNA molecule with an average of 20 nucleotides in length, regulates most of protein expression at the miRNA translational level. miRNAs delivered to recipient cells regulate gene expression by either repressing the translation or causing degradation of multiple mRNAs, depending on the cellular content. Nowadays, 2,850 of human miRNAs have been identified, each of which are estimated to control various genes [16]. 
The viral genomes, including DNA and RNA virus, are capable of encoding miRNAs. The virus-derived miRNAs can be expressed in host cells and participate in the lifecycle and cellular consequences of infection. The virus-derived miRNAs have been found to target a large number of host coding mRNAs involved in regulating cell proliferation, apoptosis, and host immunity. This biological role of miRNAs can help in the fight against viral reproduction, since the synthesis of viral proteins occurs in the host cell. The classical mechanism of miRNAs to regulate their target gene is by binding to the $3^{\prime}$ untranslated region ( $3^{\prime}$ UTR) of target mRNA to exert negative regulatory effects on gene expression. The use of miRNAs for this purpose requires with the fulfillment of a number of conditions. One of the most important point is that the selected miRNA must highly specifically bind to the target miRNA of the viral genome (gRNA) or parts of its genome [17].

There are about 80 SARS-CoV-2 encoded miRNAs that can target the virus genome. There are 2 miRNA targets at the 5' UTR of the virus genome, and 2 at the $\mathrm{S}$ gene, which encodes a spike glycoprotein to bind its receptor ACE2 on human cells, and mediates membrane fusion and virus entry. Twenty-eight human miRNAs have been predicted to have 30 targets on the SASRS-CoV-2 genome. A human miRNA, hsa-miR-4661$3 \mathrm{p}$, has been predicted to target at the genomic region $25,296-$ 25,320 within $\mathrm{S}$ gene transcript with the possible role of a repressor on the expression of S gene [18].

This observation suggested a possible repressor role of hsamiR-4661-3p on the SARS-CoV-2 S gene expression. It might be an example of the antiviral mechanism except for immune response adopted by the host to defense virus. Bronchoalveolar stem cells (BASCs) are the main cells infected by SARSCoV-2, which induces overexpression of miR-5, miR-574$5 \mathrm{p}$ and miR-214 and downregulation of miR-223 and miR98 expression. It has also reported that miR-4507, miR-638, miR-3150b-3p and miR-602 can bind conserved regions of the 5'UTR of SARS-CoV-2. These miRNAs control several stages of viral development as well as pro-inflammatory cytokine production [19].

Therefore, with the ongoing exploration of miRNAs, miRNAs' clinical application keeps continuously developing as well, among which miRNA-targeting anti-viral therapy has aroused great interest and wide concern. In addition, miRNA expression profiles offer molecular signatures for the classification, diagnosis, and progression of viral biomarkers. The miRNAs expression levels have been proven to be potentially valuable for the early diagnosis, prognosis, and prediction of the response to therapy in various types of viral infection using multiple analyses of miRNAs [20].

The miRNA plays an important role in cancer development since miRNAs are involved in cell differentiation, and regulation of cell cycle. The first paper of the special issue provides general information of miRNA in cancer research. This thematic issue presents two computational approaches for miRNA identification and their role in cancer [21].

\section{Exosomes}

Exosomes are produced by virtually all normal and pathological cells and are found in all body fluids. Intercellular communication between infected cells and with their neighbouring cells and distant organs is key to the survival pathway, progression and drug resistance. A growing body of evidence indicates that exosomes play a critical role in this cell-cell communication process.

Exosomes are biological nanoparticles with an average diameter of between 30 and $100 \mathrm{~nm}$ in size and produced by almost all cell types in the human body. The thousands of exosomes are released by a single parent cell in a day. While in response to pathological conditions, exosomes are found to be secreted in high numbers. In fact, exosomes are admirably equipped to serve as communication vehicles and their surface is decorated by the parent cell-derived signaling molecules [22].

Exosome contents not only mirror the composition of the donor cell but also reflect a regulated sorting mechanism. They are released into all body fluids (plasma, urine, saliva, amniotic fluids, ascites, cerebrospinal fluid and others) contain nucleic acids mainly miRNAs, mRNAs and specific protein biomarkers. These bioactive molecules are transferred from donor cells to target cells by exosome transport system, leading to reprogramming of the recipient cells [23].

Therefore, the specific exosomes secreted by infected cells that contain the biomarkers can be used to predict the existence of a disease [20]. Due to their small size, natural products of the body cells (non-immunogenic), non-toxic characteristics and crossing the various biological barriers, they are an excellent delivery system for anti-disease miRNAs in therapeutic tools. miRNAs encapsulated by exosomes are remarkably stable in circulation because exosomes can protect miRNA against RNase-mediated degradation [19]. Cell-derived exosomes represent a substantial part of the plasma vesicular content, and their molecular and genetic profiles change in the course of disease or therapy. Exosomes represent a hot area of research with many promising results in fighting disease with agents derived from abnormal cells [24]. 


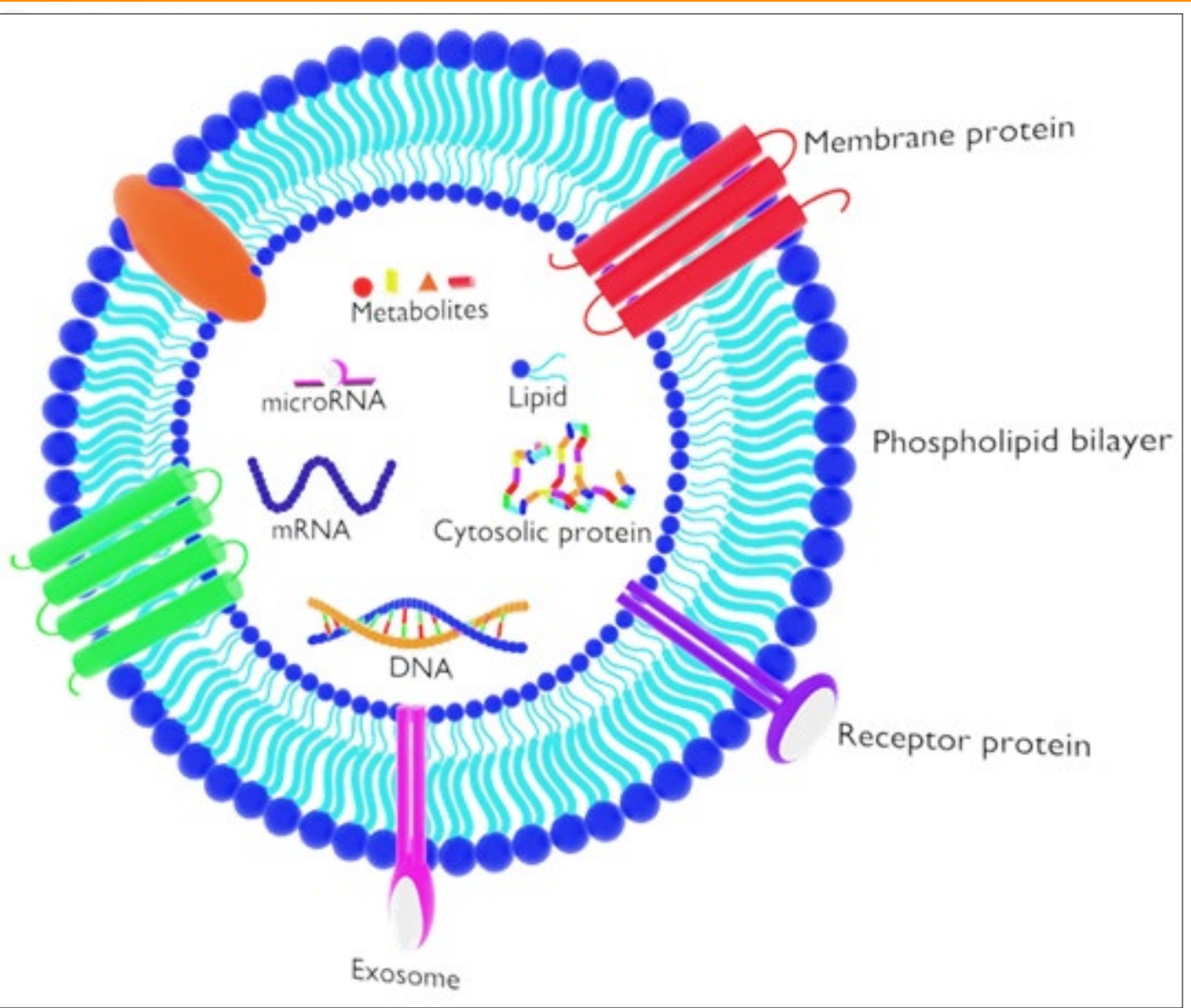

Figure 1. The structure and content of exosome. Exosomes contain various types of proteins, nucleic acids, lipids and metabolites [24] (Dilsiz N., 2020).

\section{COVID-19 Vaccination \& Podosomes}

Podosomes and invadopodia are unique actin-rich adhesions that establish close contact to the substratum but can also degrade components of the extracellular matrix. Accordingly, matrix degradation localized at podosomes or invadopodia is thought to contribute to cellular invasiveness in physiological and pathological situations. Cell types that form podosomes include monocytic, endothelial and smooth muscle cells, whereas invadopodia have been mostly observed in carcinoma cells [25].

Lecomte MC. and col in 2015 demostrated that invadosomes are actin-rich adhesion structures involved in tissue invasion and extracellular matrix (ECM) remodeling. The vaccine candidate presents in Silico an inhibiting action against $\alpha$ IIspectrin [26].

\section{Materials and Methods}

Homology modelling has evolved into an important procedure in structural biology, significantly contributing to narrowing the gap between known protein sequences from a virus and designed protein in Silico structures.

Antiviral proteins were designed to be used as protein inhibitors. The inhibition is due to protein on protein interactions. A cleavage site has been adjusted (DEVD) in the peptide to induce the caspases 3 and 7 action, and thereby apoptosis in infected cells.

On the other hand, in cells not infected apoptosis is not induced, and the synthesis of the miRNA will allow an antigen involved in production of antibodies against the Covid-19 and also HIV1 to appear.

The miRNA 3' and peptide N-terminus will both be modified for click chemistry conjugation $[11,12]$.

\section{Gene Targets:}

\section{Ontology enrichment analysis}

The primers used as miRNA targets were:

(Biolegio, Nijmegen, The Netherlands)

- NFAT3C_FW1(CTCCTAGAACTAGCATTACAGATG),

- NFAT3C_RV1(GACCAGGTGATGGAGTTGGAG),

- NFAT5_FW1(CACTGAGGTGCCACGTAAATC),

- NFAT5_RV1(GCTTTTGAGTTGCCTTTGCTG),

- SPPL3_FW2(GTAGCAGACTATTACCTACGTG),

- $\quad$ SPPL3_RV2(GAAGCTTCAGTTTGCCTAACTG),

- TGFB2_FW1(GCAAGATTTGCAGGTATTGATGAC),

- TGFB2_RV1(CCTGCACATTCCTAAAACAA),

- JUN_FW1(GCAGAGCATGACGCTGAACCTG),

- JUN_RV1(CTTGCTCGTCGGTAACGTTC), 
- IBV5'GU391_fw(GCTTTTGAGCCTAGCGTT),

- IBV5'GL533_rv(GCCATGTTGTCACTGTCTATTG),

- housekeepinggeneGAPDH FW92(GAAGGCTGGGGCTCATCTG),

- GAPDH_RV92(CAGTTGGTGGTGCACGATG),
- housekeepinggeneACTB

FW89(CAACACAGTGCTGTCTGGTGGTA)

- ACTB RV89(ATCGTACTCCTGCTTGCTGATCC).

All primers were validated for their stability after peptide fusion. Statistical analysis [27].

\begin{tabular}{|c|c|c|c|c|c|c|c|}
\hline DNA & $\mathrm{A}$ & $\mathrm{T}$ & $\mathrm{C}$ & $\mathrm{G}$ & SUMA & PRIMER & PEPTIDE \\
\hline $\mathrm{a}$ & 18 & 6 & 6 & 4 & 34 & $\begin{array}{l}\text { AAAAAAAAAA-- } \\
\text { CTCCTAGAACTAGCATTACAGATG }\end{array}$ & $\begin{array}{l}\text { CCCCC-- } \\
\text { VNCDTFCAGSTFISDEVD } \\
\text { GVDEVAKKKSK }\end{array}$ \\
\hline $\mathrm{b}$ & 13 & 4 & 2 & 10 & 29 & $\begin{array}{l}\text { AAAAAAAA-- } \\
\text { GACCAGGTGATGGAGTTGGAG }\end{array}$ & $\begin{array}{l}\text { CCCCC-- } \\
\text { VNCDTFCAGSTFISDEVD } \\
\text { GVDEVAKKKSK }\end{array}$ \\
\hline $\mathrm{c}$ & 14 & 4 & 6 & 5 & 29 & $\begin{array}{l}\text { AAAAAAAA-- } \\
\text { CACTGAGGTGCCACGTAAATC }\end{array}$ & $\begin{array}{l}\text { CCCCC-- } \\
\text { VNCDTFCAGSTFISDEVD } \\
\text { GVDEVAKKKSK }\end{array}$ \\
\hline $\mathrm{d}$ & 9 & 10 & 4 & 6 & 29 & $\begin{array}{l}\text { AAAAAAAA-- } \\
\text { GCTTTTGAGTTGCCTTTGCTG }\end{array}$ & $\begin{array}{l}\text { CCCCC-- } \\
\text { VNCDTFCAGSTFISDEVD } \\
\text { GVDEVAKKKSK }\end{array}$ \\
\hline $\mathrm{e}$ & 14 & 6 & 5 & 5 & 30 & $\begin{array}{l}\text { AAAAAAAA-- } \\
\text { GTAGCAGACTATTACCTACGTG }\end{array}$ & $\begin{array}{l}\text { CCCCC-- } \\
\text { VNCDTFCAGSTFISDEVD } \\
\text { GVDEVAKKKSK }\end{array}$ \\
\hline $\mathrm{f}$ & 13 & 7 & 5 & 5 & 30 & $\begin{array}{l}\text { AAAAAAAA-- } \\
\text { GAAGCTTCAGTTTGCCTAACTG }\end{array}$ & $\begin{array}{l}\text { CCCCC-- } \\
\text { VNCDTFCAGSTFISDEVD } \\
\text { GVDEVAKKKSK }\end{array}$ \\
\hline $\mathrm{g}$ & 15 & 7 & 3 & 7 & 32 & $\begin{array}{l}\text { AAAAAAAA-- } \\
\text { GCAAGATTTGCAGGTATTGATGAC }\end{array}$ & $\begin{array}{l}\text { CCCCC-- } \\
\text { VNCDTFCAGSTFISDEVD } \\
\text { GVDEVAKKKSK }\end{array}$ \\
\hline $\mathrm{h}$ & 16 & 4 & 7 & 1 & 28 & $\begin{array}{l}\text { AAAAAAAA-- } \\
\text { CCTGCACATTCCTAAAACAA }\end{array}$ & $\begin{array}{l}\text { CCCCC-- } \\
\text { VNCDTFCAGSTFISDEVD } \\
\text { GVDEVAKKKSK }\end{array}$ \\
\hline $\mathrm{i}$ & 14 & 3 & 6 & 7 & 30 & $\begin{array}{l}\text { AAAAAAAA-- } \\
\text { GCAGAGCATGACGCTGAACCTG }\end{array}$ & $\begin{array}{l}\text { CCCCC-- } \\
\text { VNCDTFCAGSTFISDEVD } \\
\text { GVDEVAKKKSK }\end{array}$ \\
\hline $\mathrm{j}$ & 10 & 7 & 6 & 5 & 28 & $\begin{array}{l}\text { AAAAAAAA-- } \\
\text { CTTGCTCGTCGGTAACGTTC }\end{array}$ & $\begin{array}{l}\text { CCCCC-- } \\
\text { VNCDTFCAGSTFISDEVD } \\
\text { GVDEVAKKKSK }\end{array}$ \\
\hline $\mathrm{k}$ & 10 & 7 & 4 & 5 & 26 & $\begin{array}{l}\text { AAAAAAAA-- } \\
\text { GCTTTTGAGCCTAGCGTT }\end{array}$ & $\begin{array}{l}\text { CCCCC-- } \\
\text { VNCDTFCAGSTFISDEVD } \\
\text { GVDEVAKKKSK }\end{array}$ \\
\hline 1 & 11 & 9 & 5 & 5 & 30 & $\begin{array}{l}\text { AAAAAAAA-- } \\
\text { GCCATGTTGTCACTGTCTATTG }\end{array}$ & $\begin{array}{l}\text { CCCCC-- } \\
\text { VNCDTFCAGSTFISDEVD } \\
\text { GVDEVAKKKSK }\end{array}$ \\
\hline $\mathrm{m}$ & 11 & 4 & 4 & 8 & 27 & $\begin{array}{l}\text { AAAAAAAA-- } \\
\text { GAAGGCTGGGGCTCATCTG }\end{array}$ & $\begin{array}{l}\text { CCCCC-- } \\
\text { VNCDTFCAGSTFISDEVD } \\
\text { GVDEVAKKKSK }\end{array}$ \\
\hline $\mathrm{n}$ & 11 & 5 & 3 & 8 & 27 & $\begin{array}{l}\text { AAAAAAAA-- } \\
\text { CAGTTGGTGGTGCACGATG }\end{array}$ & $\begin{array}{l}\text { CCCCC-- } \\
\text { VNCDTFCAGSTFISDEVD } \\
\text { GVDEVAKKKSK }\end{array}$ \\
\hline 0 & 13 & 6 & 5 & 7 & 31 & $\begin{array}{l}\text { AAAAAAAA-- } \\
\text { ACACAGTGCTGTCTGGTGGTA }\end{array}$ & $\begin{array}{l}\text { CCCCC-- } \\
\text { VNCDTFCAGSTFISDEVD } \\
\text { GVDEVAKKKSK }\end{array}$ \\
\hline $\mathrm{p}$ & 11 & 8 & 8 & 4 & 31 & $\begin{array}{l}\text { AAAAAAAA-- } \\
\text { ATCGTACTCCTGCTTGCTGATCC }\end{array}$ & $\begin{array}{l}\text { CCCCC-- } \\
\text { VNCDTFCAGSTFISDEVD } \\
\text { GVDEVAKKKSK }\end{array}$ \\
\hline
\end{tabular}

Table 1 shows the 16 DNA primers used as fusion with the selected peptide for the vaccine against the human Coronavirus. On the table the number of nitrogenated bases and the size of the primer can be seen. The Polyadenylation (number of Adenines adjusted at the 5 end of the primer and the number of Cys adjusted to the peptided utilized as a spacing arm between the RNA and the peptide.) [11,12]. 
This peptide begins with the aminoacid Cysteine (C) to facilitate fusion with the 5 ' of miRNA.

The peptide utilized was the following:

- $\quad$ Full peptide sequencing (34 aminoacids)

CCCCCVNCDTFCAGSTFISDEVDGVDEVAKKKSK

https://blast.ncbi.nlm.nih.gov/Blast.cgi\#alnHdr

YP 009725299

NŌN-STRUCTURAL POLYPROTEIN 1AB [BAT SARS-

LIKE CORONAVIRUS]

After cleavage of caspase $3 / 7$

I) SARS-CoV-2 (23 aminoacids)

CCCCCVNCDTFCAGSTFISDEVD

https://blast.ncbi.nlm.nih.gov/Blast.cgi\#alnHdr_QHW06038

ORF1ABPOLYPROTEIN [SEVEREACUTERESPIRATORY

SYNDROME CORONAVIRUS 2]

II) HUMAN PARP-1 (11 aminoacids)

\section{GVDEVAKKKSK}

https://blast.ncbi.nlm.nih.gov/Blast.cgi\#alnHdr_AAL02174

poly(ADP-ribose) polymerase, partial [Homo sapiens]

$$
\begin{aligned}
& a=\frac{S_{\text {Poly } A}}{S_{\text {PolyCys }}}, \quad b=\frac{M W_{\text {miRNA }}}{M W_{\text {Peptide }}}, \quad c=\frac{S_{\text {Peptide }}}{S_{\text {miRNA }}}, \\
& d=\frac{[2(A+B)+3(C+G)]}{X\left(p I_{1}, p I_{2}, \ldots, p I_{n}\right)}, \\
& S_{\text {Poly A }} \quad \text { :Poly A size } \\
& S_{\text {PolyCys } \quad: \text { Poly Cys size }} \\
& M W_{\text {miRNA }} \quad \text { : miRNA Molecular Weight } \\
& M W_{\text {Peptide }} \quad \text { :Peptide Molecular Weight } \\
& S_{\text {Peptide }} \quad \text { :Peptide size [aa] } \\
& S_{\text {miRNA }} \quad \text { :miRNA Size }
\end{aligned}
$$

$\mathbf{B}=\mathbf{T}$ if $D N A$ or $\mathbf{B}=\mathbf{U}$ if $R N A$

pI: point Isoelectric

$\mathrm{n}$ : peptide size

The mathematical formula utilized to estimate the stability of the fusion between miRNA and the selected peptide was:

$\mathrm{FS}=a b c d$, where:

Formula developed by Dr. Luis CRUZ-RODRIGUEZ and named as Fusion Stability CRUZ-RODRIGUEZ (FS) and values units in Cruz [10].

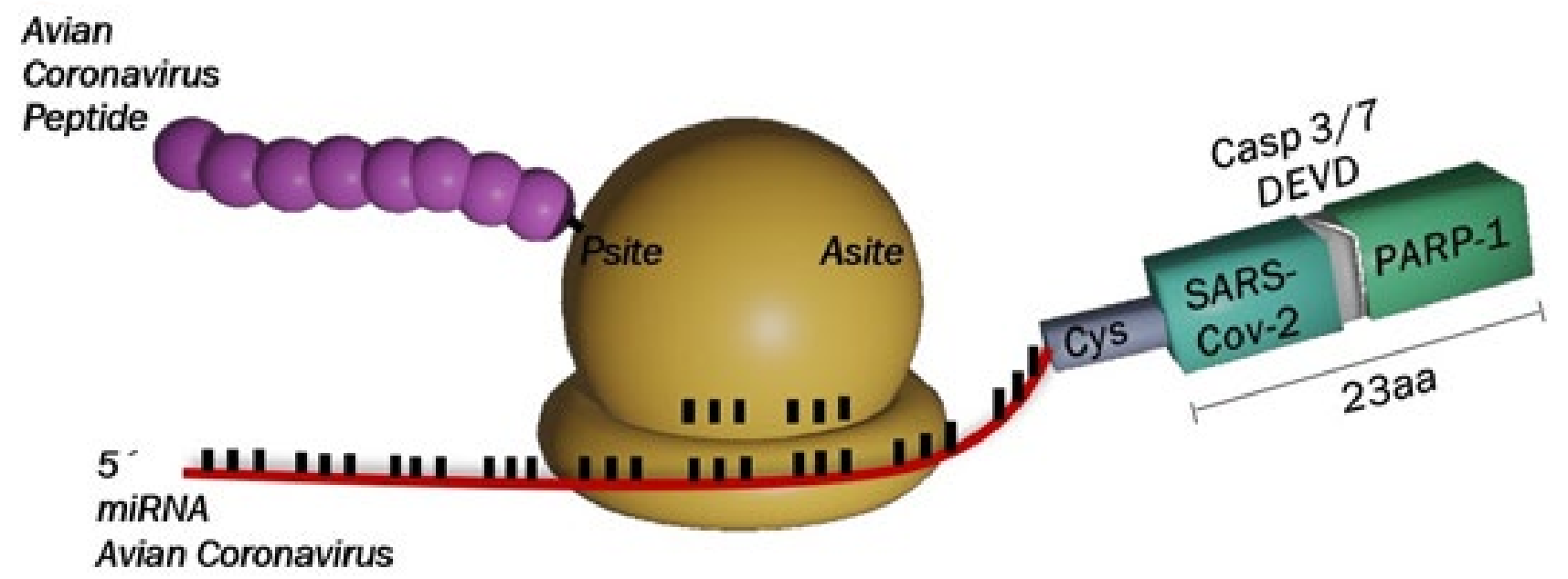

Figure 2 indicates fusion stability (FS) between primers of miRNA and peptide (spacing arm (Poly Cys) and fused molecules SARS-CoV-2 and PARP-1) and protein synthesis in ribosome. [10] [11] [12] (Cruz-Rodriguez L. 2020)

The mathematical formula utilized to estimate the Exosome

Affinity (EA) between miRNA-peptide and Exosome is:

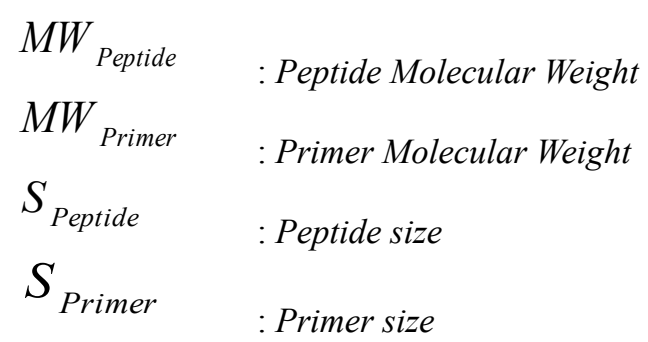

Where:

$$
E A=F S\left(\frac{M W_{\text {peptide }}}{M W_{\text {primer }}}+\frac{S_{\text {peptide }}}{S_{\text {primer }}}\right)
$$

EA: Exosome Affinity

FS: Fusion Stability

Formula developed by Dr. Luis CRUZ-RODRIGUEZ and named as Exosome Affinity CRUZ-RODRIGUEZ (EA) and values units in Ro, [28]. 


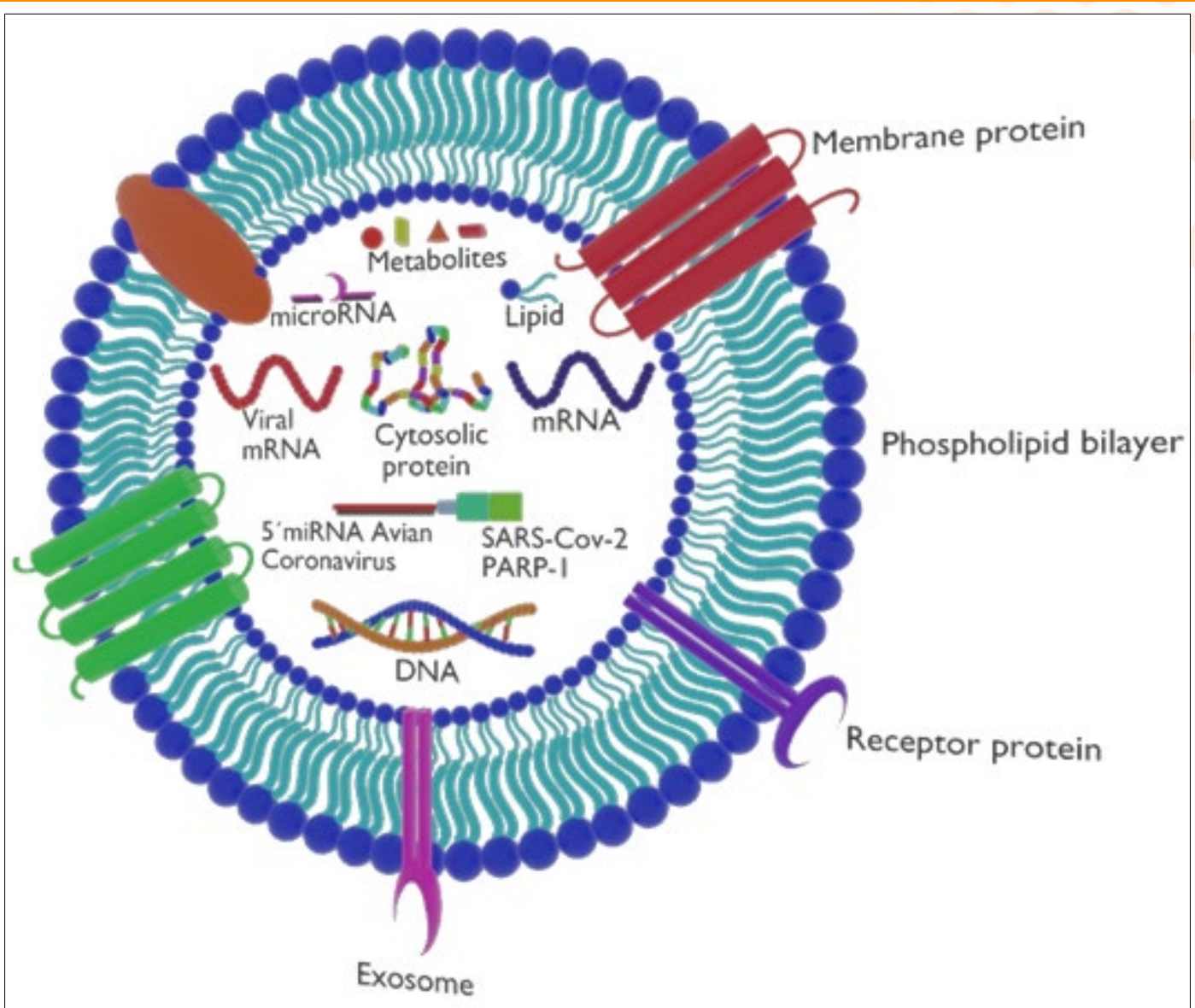

Figure 3 modified of (Dilsiz N., 2020). The structure and content of exosome with miRNA and peptide, fused molecules. Exosomes contain various types of proteins, nucleic acids, lipids and metabolites and viral mRNA [24].

\section{Results and Discussion}

\section{Bioinformatics identification of miRNAs}

Prior to analysis, readings containing poly-N, with 5' Cyspeptide fusion with a 3 ' insert tag, containing poly-A (add 8 nucleotides of Alanine to all primers except primer to which 10 nucleotides of Alanine were added). The small miRNA was clustered with a peptide with caspase site, and the percentage of differential of Fusion Stability (FS) RNA-peptide was calculated. The mapped small RNA reads were examined for the presence of known miRNAs using MiRBase20.0 (http:// www.mirba se.org/). Based on this analysis 16 vaccine candidates were identified below. The Differential miRNApeptide fusion stability curve was calculated (Fig 4).

a.NFAT3C

FW1(3'CTCCTAGAACTAGCATTACAGATG5'), 3'AAAAAAAAAA----

CTCCTAGAACTAGCATTACAGATG---CCCCCVNCDTFCAGSTFISDEVDGVDEVAKKKSK $\mathrm{FS}=64,28$

b. NFAT3C_RV1(3'GACCAGGTGATGGAGTTGGAG5'), 3'AAAAAAAA---- GACCAGGTGATGGAGTTGGAG CCCCCVNCDTFCAGSTFISDEVDGVDEVAKKKSK $\mathrm{FS}=58,93$ c. NFAT5_FW1(3'CACTGAGGTGCCACGTAAATC5'), 3'AAAAAAAA----CACTGAGGTGCCACGTAAATC--CCCCCVNCDTFCAGSTFISDEVDGVDEVAKKKSK $\mathrm{FS}=56,97$

d. NFAT5_RV1(3'GCTTTTGAGTTGCCTTTGCTG5'), 3'AAAAAAAA----GCTTTTGAGTTGCCTTTGCTG--CCCCCVNCDTFCAGSTFISDEVDGVDEVAKKKSK $\mathrm{FS}=56,21$

e. SPPL3_FW2(3'GTAGCAGACTATTACCTACGTG5'), 3'AAAAAAAA----GTAGCAGACTATTACCTACGTG--CCCCCVNCDTFCAGSTFISDEVDGVDEVAKKKSK $\mathrm{FS}=57,85$

f. SPPL3 RV2(3'GAAGCTTCAGTTTGCCTAACTG5'), 3'AAAAAAAA----GTAGCAGACTATTACCTACGTG--CCCCCVNCDTFCAGSTFISDEVDGVDEVAKKKSK $\mathrm{FS}=57,79$

g.TGFB2_FW1(3'GCAAGATTTGCAGGTATTGATGAC5'), 3'AAAAAAAA----GCAAGATTTGCAGGTATTGATGAC CCCCCVNCDTFCAGSTFISDEVDGVDEVAKKKSK $\mathrm{FS}=61,62$ 
h. TGFB2 RV1(3'CCTGCACATTCCTAAAACAA5'), 3'AAAAAAAA----CCTGCACATTCCTAAAACAA-CCCCCVNCDTFCAGSTFISDEVDGVDEVAKKKSK $\mathrm{FS}=52,29$

i. JUN_FW1(3'GCAGAGCATGACGCTGAACCTG5'), 3'AAAAAAAAA----GCAGAGCATGACGCTGAACCTG---CCCCCVNCDTFCAGSTFISDEVDGVDEVAKKKSK $\mathrm{FS}=60,55$

j. JUN_RV1(3'CTTGCTCGTCGGTAACGTTC5'), 3'AAAAAAAA----CTTGCTCGTCGGTAACGTTC CCCCCVNCDTFCAGSTFISDEVDGVDEVAKKKSK $\mathrm{FS}=55,13$

\section{k. IBV5'GU391_FW(3'GCTTTTGAGCCTAGCGTT5'), 3'AAAAAAAA----GCTTTTGAGCCTAGCGTT ---- CCCCCVNCDTFCAGSTFISDEVDGVDEVAKKKSK $\mathrm{FS}=50,44$}

1. IBV5'GL533_RV(3'GCCATGTTGTCACTGTCTATTG5'), 3'AAAAAAAA----GCCATGTTGTCACTGTCTATTG--CCCCCVNCDTFCAGSTFISDEVDGVDEVAKKKSK $\mathrm{FS}=57,68$ m. GAPDH FW92(3'GAAGGCTGGGGCTCATCTG5'), 3'AAAAAAAA---- GAAGGCTGGGGCTCATCTG ---CCCCCVNCDTFCAGSTFISDEVDGVDEVAKKKSK $\mathrm{FS}=55,09$

n. GAPDH_RV92(3'CAGTTGGTGGTGCACGATG5'), 3'AAAAAAAA---- CAGTTGGTGGTGCACGATG ---CCCCCVNCDTFCAGSTFISDEVDGVDEVAKKKSK $\mathrm{FS}=54,34$

o. ACTB_FW89(3'CAACACAGTGCTGTCTGGTGGTA5'), 3'AAAAAAAA----CAACACAGTGCTGTCTGGTGGTA--CCCCCVNCDTFCAGSTFISDEVDGVDEVAKKKSK $\mathrm{FS}=61,37$

p. ACTB_RV89(3'ATCGTACTCCTGCTTGCTGATCC5'). 3'AAAAAAAA----ATCGTACTCCTGCTTGCTGATCC CCCCCVNCDTFCAGSTFISDEVDGVDEVAKKKSK $\mathrm{FS}=60,50$

a, b, c, d, e, f, g, h, I, j, k, l, m, n. o, p: are sixteen DNApeptide fusion candidates. The DNA primer is translated to RNA for the proposed vaccine against the Covid19 [29].

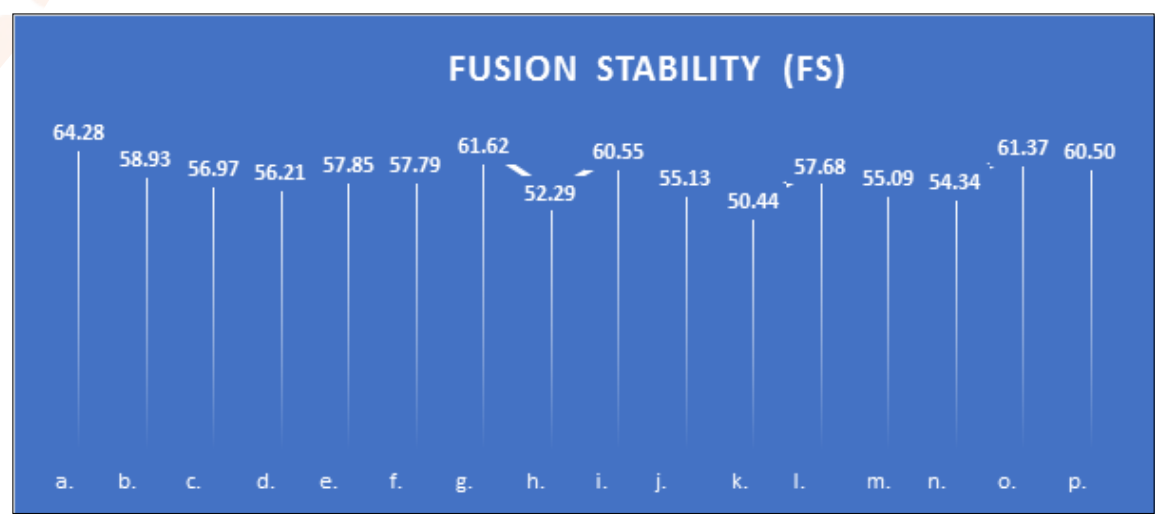

Figure 4 shows the stability value of the fusion among different DNA: a, b, c, d, e, f, g, h, I, j, k, l, m, n. o, p).

The fusion stability most representative was $64.28 \mathrm{Cruz}$ and was named: ANTIVIRAL CHEMICAL CHIMERA FORMULA LCR_2020_B008-1: Antiviral chemical chimera formula: against Human Coronavirus (Covid19) (Fig 5) [10].

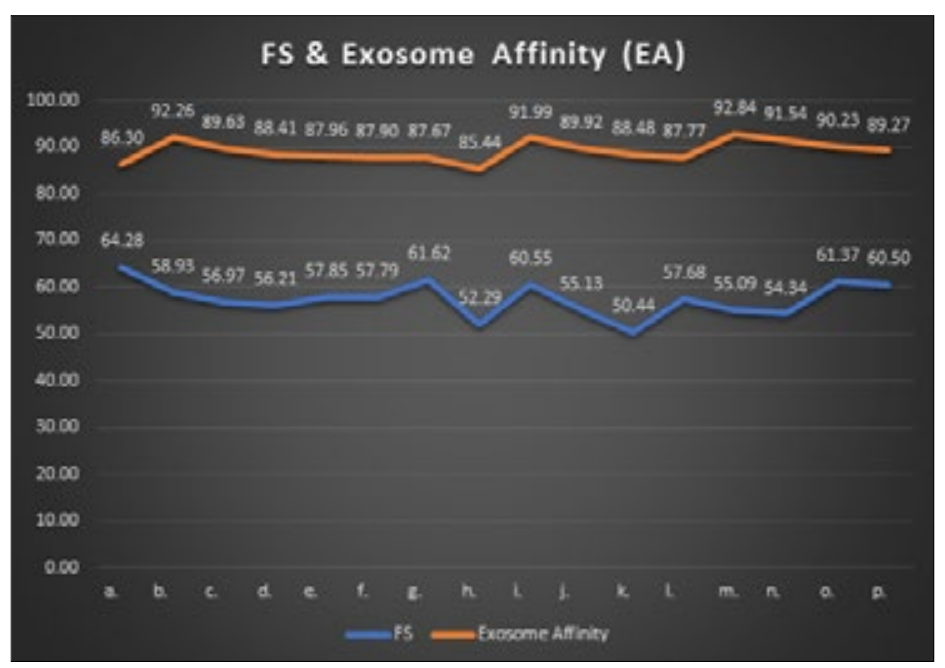

Figure 5 shows the stability value Vs Exosome affinity among different miRNA-peptide: a, b, c, d, e, f, g, h, I, j, k, l, m, n. o, p The 
Exosome Affinity most representative was 92.84 Ro and was named: ANTIVIRAL CHEMICAL CHIMERA FORMULA LCR_2020_B008-13: Antiviral chemical chimera formula: against Human Coronavirus (Covid-19) [28].

\section{Candidate selected:}

miRNA-peptide:

m. 5'(AAAAAAAA----GAAGGCUGGGGCUCAUCUG)3'

(N-ter)

CCCCCVNCDTFCAGSTFISDEVDGVDEVAKKKSK

(C-ter)

$$
\mathrm{EA}=92.84 \text { Ro }
$$

Using ProMod3 and the introduction a new local model quality estimation method, QMEANDisCo. SWISS-MODEL (https:// swissmodel.expasy.org). Here, we present an update to the SWISS-MODEL server, with several candidates of antiviral Covid19 vaccine miRNA-peptide [27] .

https://swissmodel.expasy.org/interactive/88DDHj/models/

From candidate selected: LCR_2020_B008-13

miRNA poly-A (27 nt)-peptide (34 aa)

5'(AAAAAAAA----GAAGGCUGGGGCUCAUCUG)3'

(N-ter)

CCCCCVNCDTFCAGSTFISDEVDGVDEVAKKKSK

(C-ter)

We present an update to: miRNA, full peptide sequencing and the two peptides after caspase $3 / 7$ cleavage.

- miRNA + Poly-A (27 nt) fusion peptide (SARS-Cov-2 (23 aa) + PARP-1 (11 aa))

5'(AAAAAAAA----GAAGGCUGGGGCUCAUCUG)3' ---(N-ter)

CCCCCVNCDTFCAGSTFISDEVDGVDEVAKKKSK

(C-ter)

https://blast.ncbi.nlm.nih.gov/Blast.cgi\#1797068551

Leptospira interrogans serovar Copenhageni strain SK1 chromosome I

- $\operatorname{miRNA}(19 \mathrm{nt})$

5' GAAGGCUGGGGCUCAUCUG

https://blast.ncbi.nlm.nih.gov/Blast.cgi\#1390069545

Phasianus colchicus nuclear factor of activated $\mathrm{T}$ cells 3

(NFATC3), transcript variant X1, miRNA. [30]

\section{Conclusions and Perspectives}

Our analysis in Silico identified a stable fusion miRNApeptide from 16 vaccine candidates aimed with high affinity for exosomes to prevent and treatment Covid19 infections [29]. The vaccine candidate with the highest FS was named: LCR_2020_B008-13

It presents a cleavage site for enzymes Caspase-3 and caspase-7 are both activated universally during apoptosis, irrespective of the specific death-initiating stimulus, and both proteases are widely considered to coordinate the demolition phase of apoptosis by cleaving as a protein substrate. Inoculation is expected to be orally with appropriate doses.

With regards to the antiviral action, the candidate manifests LCR_2020_B008-1, in Silico, manifests a partial inhibiting activity on the HIV-1 and HIV-2, which means that readjustments in this chimera miRNA-peptide could reach a representative tripe antiviral activity against the VIH-1/2 and Covid19 [30,31].

\section{Perspectives \\ At short time:}

These miRNAs can be used as therapeutic agents by incorporating them into exosomes or other vesicles and introducing them into the blood or lung by inhalation. The introduction of selected miRNAs into the blood will suppress the reproduction of the virus in the blood and in all organs into which it cancer [32]. The future proposed method of inhibiting the reproduction of coronaviruses can also be used for other viruses $[33,34]$.

The SARS-CoV-2 entries cells by engaging the human angiotensin-converting enzyme 2 (ACE2) as receptor with the external surface unit of N-terminal (S1) of the spike (S) protein, and then uses the host transmembrane serine protease 2 (TMPRSS2) for S protein priming, allowing fusion of viral and cellular membranes and the viral RNA genome entry mainly into the cytoplasm of epithelial cells of lung alveoli, liver, heart, kidney, brain and intestine [35,36,37]. The virus then matures, produces multiple copies, and escapes from the host cells to infect new cells. Therefore, the mRNA region of this protein in the viral genome represents a good target for non-coding miRNA development by using exosome against to the spike mRNA of SARS-CoV-2. In this case the viral spike mRNA translation will be blocked after hybridization with the selected complementary miRNAs. Also, a synthetic miRNA can be used to inhibit viral genomic mRNA replication by reducing the expression of RNA-dependent RNA polymerase (RdRp) [38].

\section{References}

1. Zhu N, Zhang D, Wang W, Li X, Yang B, Song J, Zhao X, Huang B, Shi W, Lu R, Niu P, Zhan F, Ma X, Wang D, Xu W, Wu G, Gao GF, Tan W (2020) "A Novel Coronavirus from Patients with Pneumonia in China, 2019.” N Engl J Med 382(8): 727-733. doi: 10.1056/NEJMoa2001017

2. Wang Z (2020)"A Handbook of 2019-nCoV Pneumonia Control and Prevention", Hubei Science and Technology Press. January 2020.

3. Cascella M, Rajnik M, Cuomo A, Dulebohn SC, Di Napoli R (2020) "Features, Evaluation and Treatment Coronavirus (COVID-19)", SourceStatPearls [Internet]. Treasure Island (FL): StatPearls Publishing; 2020-Mar 8.

4. Centeno JA, Finkelman RB. and Selinus O (2016) "Medical Geology: Impacts of the Natural. Environment on Public Health": Geosciences 2016, 6, 8; doi:10.3390/ geosciences 6010008 . 
5. Selinus O, Alloway B, Centeno JA, Finkelman RB, Fuge R, Lindh U, Smedley, P. (Editors)(2005) "Essentials of Medical Geology". Elsevier, Amsterdam, 820 p. (second edition published by Springer 2012).

6. Selinus O, Finkelman B, Centeno JA (2009) Editors." Medical Geology - a regional synthesis”. Springer. 2010.

7. Hochwimmer B, Cruz-Rodriguez L (2005) "The Polygonal Vortex Mineralisation Model: a predictive tool of health indices and the proposed use of such "geologically based public health indices as a sub discipline of Medical Geology". 2005, ISBN 9697117037.

8. Cruz-Rodriguez L, Hochwimmer B, Selinus O (2005) "Medical Geology in Cuba". 2005, ISBN 9697117037.

9. Hochwimmer B, Ziarati P, Selinus O, Elwej A, Lambert Brown D, Zayas Tamayo AM, Moradi M, Cruz-Rodriguez L (2020) "A predictive geological tool of Type3 Diabetes (Alzheimer's disease) : The Polygonal Vortex Mineralisation Model a medical geology perspective" ; Journal of Diabetes and Endocrinology Research 2020 April, 2020 Volume 2, Issue 2, https:/unisciencepub.com/ wp-content/uploads/2020/04/A-Predictive-GeologicalTool-of-Type-3-Diabetes-The-Polygonal-Vor.pdf

10. Cruz-Rodriguez L, Cruz-Rodriguez LD, Sanchez Batista L, Hochwimmer B (2020)"Calculation of Fusion Stability of [DNA or RNA] - Peptide (FS) Algorithm *CruzRodriguez*” J B \& Bio Engine ; 2020, vol 2, issue 1. https://unisciencepub.com/wp-content/uploads/2020/05/ CALCULATION-OF-FUSION-STABILITY-OFDNA-OR-RNA-PEPTIDE-FS-ALGORITHM-CRUZRODRIGUEZ.pdf

11. Cruz-Rodriguez L, Lambert Brown D, Hochwimmer B, Selinus O, Cruz-Rodriguez LD, Cruz-Rodriguez ME, Hochwimmer BAM, Sanchez Batista L (2020) "A RNAPeptide fusion as a vaccine candidate against the novel Coronavirus (COVID-19)"; Journal of Diabetes and Endocrinology Research 2020 April 2nd, 2020: J Diabetes Endocrinol Res; 2020: vol 2 isuue 1. https://unisciencepub. com/wp-content/uploads/2020/04/A-miRNA-PEPTIDEFUSION-AS-A-VACCINE-CANDIDATE-AGAINSTTHE-NOVEL-CORONAVIRUS-COVID-19.pdf

12. Cruz-Rodriguez L, Zayas Tamayo AM, Sanchez Batista L, Lambert Brown D, Hochwimmer B, Ziarati P (2020) "A Novel vaccine candidate with double antiviral activity against the HIV-1 and Covid-19": International Journal of Infectious Diseases and Research,IJ Infectious Disea; 2020 : https://unisciencepub.com/wp-content/uploads/2020/05/ A-Novel-Vaccine-Candidate-with-Double-AntiviralActivity-against-the-Hiv-1-and-Covid-19.pdf

13. Jiang W, Ma P, Deng L, Liu Z, Wang X, Liu X, Long G (2020)"Hepatitis A virus structural protein $\mathrm{pX}$ interacts with ALIX and promotes the secretion of virions and foreign proteins through exosomelike vesicles"J Extracell Vesicles 9(1) :1716513. doi: 10.1080/20013078.2020.1716513. eCollection 2020.

14. Kang S, Peng W, Zhu Y, Lu S, Zhou M, Lin W, Deng M (2020) "Recent Progress in understanding 2019 Novel Coronavirus associated with Human Respiratory Disease: Detection, Mechanism and Treatment". International
Journal of Antimicrobial Agents, 105950, 29.

15. Matias-Garcia, PR, Wilson R, Mussack V, Reischl E, Waldenberger M, Gieger C, Kuehn-Steven, A (2020) "Impact of long-term storage and freeze-thawing on eight circulating microRNAs in plasma samples". 2020: PloS one, 15(1), e0227648.

16. Bellingham SA, Shambrook M, Hill AF (2017) "Quantitative analysis of exosomal miRNA via qPCR and digital PCR". In Exosomes and Microvesicles (pp. 55-70). Humana Press, New York, NY.: 2017.

17. Ivashchenko A, Rakhmetullina A, Aisina D (2020) "How miRNAs can protect humans from coronaviruses COVID-19, SARS-CoV, and MERS-CoV":2020

18. Grundhoff A (2011) "Computational Prediction of Viral miRNAs. In Antiviral RNAi: Concepts, Methods, and Applications" (ed. van Rij, R. P.) 143-152 (Humana Press, 2011). doi:10.1007/978-1-61779-037-9_8.

19. Baldassarre A, Paolini A, Bruno SP, Felli C, Tozzi AE, Masotti A (2020) "Non-Coding RNAs and Innovative Therapeutic Strategies to Target the 5'UTR of SARSCoV-2": 2020.

20. Venturella M, Carpi FM, Zocco D (2019) “Standardization of blood collection and processing for the diagnostic use of extracellular vesicles". 2019: Current Pathobiology Reports 7(1): 1-8.

21. Tutar Y (2014) "miRNA and cancer; computational and experimental approaches": Curr Pharm Biotechnol 15(5): 429.

22. Jie-Mei Wang, Yining Qiu, Zhao Yang, Hyunbae Kim, Qingwen Qian, Qinghua Sun, Chunbin Zhang, Lei Yin, Deyu Fang,Sung Hong Back, Randal J. Kaufman, Ling Yang, and Kezhong Zhang (2018)'IRE1 $\alpha$ prevents hepatic steatosis by processing and promoting the degradation of select microRNAs":Sci Signal 11(530): eaao4617.

23. Grundhoff A (2011) "Computational Prediction of Viral miRNAs. In Antiviral RNAi: Concepts, Methods, and Applications" (ed. van Rij, R. P.) 143-152 (Humana Press, 2011). doi:10.1007/978-1-61779-037-9_8.

24. Dilsiz N (2020) "Role of exosomes and exosomal microRNAs in cancer". 2020: Future Science OA, (0), FSO465.

25. Linder S (2007) "The matrix corroded: podosomes and invadopodia in extracellular matrix degradation": Trends Cell Biol 17(3):107-17. Epub 2007

26. Ponceau A, Albigès-Rizo $C$, Yves Colin-Aronovicz, Destaing O, Lecomte MC (2015) " $\alpha$ II-Spectrin Regulates Invadosome Stability and Extracellular Matrix Degradation": PLoS One. 2015; 10(4): e0120781.

27. Waterhouse A, Bertoni M, Bienert S, Studer G, Tauriello G, Gumienny R, Heer FT, de Beer TAP, Rempfer C, Bordoli L, Lepore R, Schwede T (2018) "SWISSMODEL: homology modelling of protein structures and complexes", Nucleic Acids Res. 2018 Jul 2;46(W1): W296-W303. doi: 10.1093/nar/gky427.

28. Cruz-Rodriguez L, Sanchez Batista L, Rodriguez Valladares R, Hochwimmer B: "Calculation of Exosome Affinity (EA) and values in Ro. Algorithm "Rodriguez" “" (Article in Revision) 
29. Kemp V, Laconi A, Cocciolo G, Berends AJ, Breit T, Verheije MH (2020) “ miRNA repertoire and host immune factor regulation upon avian coronavirus infection in eggs", Archives of Virology 165: 835-843.https://doi. org/10.1007/s00705-020-04527-4. Grunt M, Failla AV, Stevic I, Hillebrand T, Schwarzenbach H (2020) "A novel assay for exosomal and cell-free miRNA isolation and quantification". 2020: RNA biology, 17(4): 425-440.

30. Liu Z, Wang J, Xu Y, Guo M, Mi K, Xu R, Hu Z (2020) "Implications of the virus-encoded miRNA and host miRNA in the pathogenicity of SARS-CoV-2".2020: arXiv preprint arXiv:2004.04874.

31. Kuate S, Cinatl J, Doerr HW, Überla K (2007) “Exosomal vaccines containing the $\mathrm{S}$ protein of the SARS coronavirus induce high levels of neutralizing antibodies". Virology, 362(1), 26-37.

32. Leon-Icaza SA, Zeng M, Rosas-Taraco AG (2020) "microRNAs in viral acute respiratory infections: immune regulation, biomarkers, therapy, and vaccines".2020 ExRNA, 1(1): 1 .

33. Naeli P, Yousefi F, Ghasemi Y, Savardashtaki A, Mirzaei H (2020) "The role of microRNAs in Lung Cancer: Implications for diagnosis and therapy". Current Molecular Medicine. 2020

34. Shiek A, Paramasivam P, Raj K, Kumar V, Murugesan R, RamaKrishanan V (2020) "Interplay of host regulatory network on SARS-CoV-2 binding and replication machinery". bioRxiv:2020.

35. Liu, Z., Wang, J., Xu, Y., Guo, M., Mi, K., Xu, R, ... \& Hu, Z. (2020). Implications of the virus-encoded miRNA and host miRNA in the pathogenicity of SARS-CoV-2. arXiv preprint arXiv:2004.04874.

36. Hoffmann, M., Kleine-Weber, H., Schroeder, S., Krüger, N., Herrler, T., Erichsen, S., ... \& Müller, M. A. (2020). SARS-CoV-2 cell entry depends on ACE2 and TMPRSS2 and is blocked by a clinically proven protease inhibitor. Cell. 181 (2), 271-280.

37. Zhou, P.; Yang, X.L.; Wang, X.G.; Hu, B.; Zhang, L.; Zhang, W.; Si, H.R.; Zhu, Y.; Li, B.; Huang, C.L.; et al. (2020). A pneumonia outbreak associated with a new coronavirus of probable bat origin. Nature, 579, 270-273.

38. Kang, S., Peng, W., Zhu, Y., Lu, S., Zhou, M., Lin, W., ...\& Deng, M. (2020). Recent Progress in understanding 2019 Novel Coronavirus associated with Human Respiratory Disease: Detection, Mechanism and Treatment. International Journal of Antimicrobial Agents, 55, (5), 105950 .

Copyright: C2020 CRUZ-RODRIGUEZ Luis. This is an open-access article distributed under the terms of the Creative Commons Attribution License, which permits unrestricted use, distribution, and reproduction in any medium, provided the original author and source are credited. 